\title{
MUDANÇAS NA AÇÃO DE PROFESSORES DE LÍNGUA PORTUGUESA DO ENSINO MÉDIO PARA PROMOÇÃO DO LETRAMENTO LITERÁRIO.
}

Rodrigo Alves dos Santos ${ }^{1}$

Resumo: Quando se trata de discutir ações para a promoção de um letramento que forme, de fato, usuários competentes da língua portuguesa, o ensino médio brasileiro é, sem sombra de dúvidas, um contexto que requer uma reflexão mais apurada, dadas a suas dificuldades de entregar para a sociedade jovens com uma qualificação minimamente desejável para egressos desse nível de formação. Nesse âmbito dos anos finais da educação básica brasileira, mais complexa ainda é a questão da formação do leitor crítico de textos literários desejado pelos discursos oficiais que regulam o ensino de língua materna no país. Ante a esse cenário, o presente ensaio vem refletir sobre as alterações que as novas perspectivas teóricas para o ensino de língua materna impõem ao trato com o texto literário no universo da sala de aula do ensino médio e sobre como tais alterações apontam para a necessidade de que também a ação do professor de língua portuguesa nesse contexto se modifique. Trata-se, aqui, de uma reflexão que vem atender a uma demanda de professores de língua portuguesa dos anos finais da educação básica brasileira que, em vários cursos de formação continuada, sempre questionam sobre que novos direcionamentos podem ser aplicados aos modos de conduzir a abordagem do texto literário junto ao público jovem que o ensino médio brasileiro potencialmente atende.

Palavras-chave: Trabalho com a leitura literária. Letramento Literário. Ensino Médio. Ação Docente.

\section{Palavras Iniciais}

Quais são as alterações sofridas pelas teorizações que dão suporte ao trabalho do/a professor/a de língua portuguesa que atua nos anos finais da educação básica brasileira em tempos recentes? Como essas alterações vêm impactando as concepções de escola, de sala de aula, de papel de professor e de aluno no âmbito do ensino de língua materna, em particular no que se refere à formação de leitores críticos de textos literários que os discursos oficiais que regulam a educação formal brasileira vêm desejando desde os anos finais do século XX? Que ações efetivas, realizadas por professores de língua portuguesa do ensino médio, podem contribuir para a promoção dos letramentos de que tanto se falam neste século $\mathrm{XXI}$, sobretudo do letramento literário?

Neste ensaio, fruto de provocações feitas por docentes em efetivo exercício do magistério participantes de cursos de formação continuada de professores em

\footnotetext{
${ }^{1}$ Professor de Língua Portuguesa, Literatura e Cultura do Departamento de Formação Geral do CEFET-MG Divinópolis. Professor do Programa de Pós-Graduação em Educação Profissional e Tecnológica (ProfEPT). Doutor em Educação pela FaE-UFMG.
} 
diferentes realidades, apresentam-se respostas às perguntas feitas acima, sem a intenção de que sejam definitivas. O desejo, com estes escritos, é a proposição de uma reflexão que, sem dispensar a leitura dos muitos textos teóricos acionados nas duas primeiras partes, possa ser objeto de interações entre professores de língua portuguesa e formadores desses professores, de moda a fomentar formas positivas de alterar a prática docente e, com isso, promover mudanças em favor da promoção do letramento do público que frequenta as escolas de ensino médio no país, em particular as escolas públicas. Mudanças essas sugeridas a partir de um exercício imaginativo que compõe a terceira parte do presente texto.

\section{Teorizações sobre os letramentos e sua repercussão sobre a ação do professor de língua portuguesa na abordagem do texto literário.}

O substantivo letramento se popularizou no Brasil sobretudo a partir dos trabalhos das professoras e pesquisadoras Magda Soares e Ângela Kleiman. Tais trabalhos tiveram ampla divulgação no país sobretudo a partir de meados dos anos 1980, exercendo grande influência, inclusive, sobre o discurso regulador do ensino de Língua Portuguesa nas escolas (SANTOS, 2009), como o veiculado nos Parâmetros Curriculares Nacionais e documentos dele derivados (BRASIL, 1999, 2002, 2006), entre os anos finais do século XX e a primeira década do século XXI.

Nesse movimento de popularização do termo, o substantivo letramento passou, principalmente nas primeiras décadas deste século XXI, a receber, no Brasil, diversas adjetivações que procuraram se referir a diferentes práticas sociais de leitura e escrita, ora levando em consideração o suporte textual (p.ex. letramento digital), ora a esfera de circulação dos textos (p.ex. letramento literário), ora a intencionalidade dos autores (p. ex. letramento político), ora o alcance social proporcionado pelo domínio de certos artefatos produzidos em torno da cultura e das formas de materialização da linguagem (p.ex. letramento cultural). Assim, para aqueles mais ambientados com o discurso acadêmico e regulador oficial brasileiro que toma como objeto a escolarização da literatura, tornou-se comum o contado com a expressão letramento literário, a qual passou a ser utilizada, no país, para se referir às finalidades do trabalho com a leitura 
literária em espaços escolares e não escolares, sobretudo nas pesquisas e publicações realizadas no âmbito do Grupo de Pesquisa do Letramento Literário, do Centro de Alfabetização, Leitura e Escrita da Faculdade de Educação da Universidade Federal de Minas Gerais. Grupo para o qual o letramento literário se configura como uma das (assim chamadas) muitas facetas do letramento, termo que, por sua vez, segundo Soares (2004, p.17), "trata-se, sem dúvida, da versão, para o Português [do Brasil] da palavra inglesa literacy".

Com relação ao termo letramento, Kleiman (1995a,b), afirma que ele teria sido cunhado, em português, por Mary Khato, na obra No mundo da escrita, publicada pela editora Ática, em 1986. Inscrito nesse âmbito, o letramento literário, segundo Paulino (1998), "como outros tipos de letramento, continua sendo uma apropriação pessoal de práticas de leitura/escrita, que não se reduzem à escola, embora passem por ela" (1998, p.16). Nesse sentido, a leitura de textos literários, assim como a leitura de outros textos que circulam socialmente, deveria ser compreendida como algo que

\begin{abstract}
se estende da habilidade de traduzir em sons sílabas sem sentido a habilidades cognitivas e metacognitivas; inclui, dentre outras: a habilidade de decodificar símbolos escritos; a habilidade de captar significados; a capacidade de interpretar sequências de ideias ou eventos, analogias, comparações, linguagem figurada, relações complexas, anáforas; e, ainda, a habilidade de fazer previsões iniciais sobre o sentido do texto, de construir significado combinando conhecimentos prévios e informação textual, de monitorar a compreensão e modificar o significado do que foi lido, tirando conclusões e fazendo julgamentos sobre o conteúdo (SOARES, 2004, p. 69).
\end{abstract}

No âmbito do letramento literário, principalmente no que se refere às formas de se configurar uma pedagogia da abordagem do texto literário em sala de aula, grande respaldo tem sido dado, no Brasil, às proposições do COSSON (2014), que estabelece quatro passos para tal finalidade: motivação, introdução, leitura e interpretação.

Sendo, na visão do autor, uma etapa determinante na abordagem do texto literário, a motivação consistiria na(s) estratégia(s) adotada(s) pelo professor para colocar o aluno-leitor em contato com o texto selecionado. Seria, portanto, uma etapa que antecederia o contato com o texto em si, consistindo na construção de 
uma situação que, sem silenciar o texto ou o leitor (COSSON, 2014, p. 56), levasse em consideração os inúmeros aspectos que poderiam motivar alguém a ler um texto literário: pessoal, familiar, cultural, político, histórico.... Caberia, assim, ao professor, identificar esses aspectos, inclusive estabelecendo, se possível, entre eles, um grau de prioridade.

Já a etapa da introdução seria, ainda de acordo com Cosson (2014), a de apresentação do autor e do texto (aqui também entendido como a obra) selecionados. Segundo o pesquisador, essa seria uma etapa na qual o professor deveria se ater apenas às informações claramente necessárias para potencializar a leitura a ser realizada, sem incorrer no velho hábito de demorar na história de vida do autor ou mesmo no percurso histórico da obra. Nesse processo, Cosson (2014) chama atenção, em suas proposições, para a importância de colocar o leitor em contato com a obra propriamente dita - mesmo que seja apenas com o volume original do professor - e de se explorar os paratextos que a compõem, como orelhas, comentários de capa, entre outros.

Etapa central no processo de leitura do texto literário proposto por Cosson (2014), a leitura seria o momento de contato efetivo do leitor com o texto que, em se tratando de uma produção breve (como um poema), poderia se aguardado pelo docente, com este se "ausentando" do processo de leitura realizado pelo aluno. No entanto, em se tratando de produções mais extensas (textos maiores ou obras completas), caberia ao professor monitorar esse momento de leitura por meio do que o autor chama de intervalos, os quais poderiam ser materializados sob a forma de conversas ou atividades de leitura de outros textos com a finalidade de resolver "problemas ligados ao vocabulário e à estrutura composicional do texto, entre outras dificuldades ligadas à decifração" (COSSON, 2014, p.64).

Cosson (2014) divide a interpretação - última etapa de sua proposição de abordagem do texto literário em sala de aula - em dois momentos: o interno e o externo. Referindo-se ao contato direto do leitor com a obra, o primeiro momento seria o do contato com o artefato literário selecionado em si, considerando desde a seleção vocabular até a construção da trama. Tratar-se-ia, portanto, de um momento que não deveria contar com os artifícios costumeiramente utilizados na escola para evitar esse "encontro" leitor/obra original, como substituir a leitura da 
obra por um resumo ou por uma adaptação cinematográfica/televisiva. Este seria, portanto, um processo individual e diretamente ligado à experiência literária do leitor, enquanto o momento externo - o segundo momento da interpretação - seria aquele em que o leitor externalizaria a sua experiência de leitura. Assim, esse segundo momento seria o compartilhamento da experiência pessoal de leitura com os demais membros da comunidade de leitores em que o leitor estaria inserido, o qual deveria ser cuidadosamente mediado pelo docente, de modo a não permitir, por um lado, o cerceamento da interpretação individual, e, por outro, a extrapolação dos limites de interpretação impostos pelo próprio texto.

Mais recentemente, no início desta segunda década do século XXI, grande visibilidade passou a ser dada ao termo multiletramentos, bastante popularizado entre pesquisadores e professores do universo das Letras e da Educação brasileiros a partir dos trabalhos de Roxane Rojo, pesquisadora com vasta experiência em ensino de língua portuguesa, doutora em Linguística Aplicada pela Pontifícia Universidade Católica de São Paulo (PUC-SP) e professora no Instituto de Estudos da Linguagem (IEL) da Universidade Estadual de Campinas (UNICAMP).

Entre os inúmeros trabalhos desta autora e de grupos de estudiosos com os quais ela trabalha, o volume Multiletramentos na escola (ROJO, MOURA 2012) tem repercutido bastante nos cursos de formação inicial e continuada de professores do país. Nesta obra, um breve histórico sobre a pedagogia dos multiletramentos aponta que ela surgiu em um grupo de pesquisadores americanos do tema - o New London Group - que, como resultado de um Colóquio, em 1996, publicou um manifesto intitulado Uma pedagogia dos multiletramentos - desenhando futuros sociais. Segundo o que se lê no texto de Rojo e Moura (2012), tal manifesto se tratava de um texto que, em linhas gerais, defendia a demanda para que a instituição escolar passasse a se dedicar à promoção dos novos letramentos característicos da sociedade atual, grande parte deles mediados pelas Tecnologias de Informação e Comunicação (TIC).

Sob essa perspectiva, conforme elucidam Rojo e Moura (2012), o ato de ler envolveria articular diferentes modalidades de linguagem além da escrita, como a imagem (estática e em movimento), a fala e a música. Nesse sentido, refletindo 
as mudanças sociais e tecnológicas atuais, ampliar-se-iam e diversificar-se-iam não só as maneiras de disponibilizar e compartilhar informações e conhecimentos, mas também de lê-los e produzi-los. Nesse âmbito, o desenvolvimento de linguagens híbridas constituiria, dessa forma, um desafio para os leitores e para os agentes que trabalham com a língua escrita, entre eles, a escola e os professores.

Ainda em conformidade com Rojo e Moura (2012), nos multiletramentos, os textos se pautariam em algumas características importantes: a) são interativos (colaborativos); b) fraturam e transgridem as relações de poder estabelecidas; e c) são híbridos, fronteiriços, mestiços (de linguagens, modos, mídias e culturas) (ROJO; MOURA, 2012,p. 23). Essas características imporiam, assim, um novo modo de conceber, por exemplo, a autoria e a recepção dos enunciados. Ou seja, o processo de produção textual deixaria de ser exclusivamente linguístico, passando a integrar itens como imagem, som, movimento; além disso, não se vivenciaria mais uma produção estritamente individual ou de mão única (alunoprofessor), mas colaborativa - mais de um sujeito contribuiria para a produção e retextualização. Portanto, esses objetos discursivos (hipermodais, polifônicos...) desafiariam a repensar as concepções enunciativas de produção e de leitura de enunciados.

Em paralelo a toda essa discussão sobre as formas de desenvolver os multiletramentos na escola, Rildo Cosson, veio, mais recentemente, refinando suas proposições sobre letramento literário por meio de declarações como:

\begin{abstract}
Aqui o letramento é menos uma prática social da escrita do que um processo de construção dos sentidos que se efetiva individual e socialmente; e o literário deixa de ser aplicado apenas a um conjunto de textos, para ser reconhecido como repertório cultural constituído por uma grande variedade de textos e atividades que proporcionam uma forma muito singular - literária - de construção dos sentidos. [...] Pensado dessa maneira, o letramento literário não se restringe ao campo escolar, embora se reconheça o impacto da escola e da academia como instituição central na manutenção e reprodução de protocolos de leitura, sendo de sua responsabilidade o desenvolvimento sistemático da competência literária. (COSSON, 2015, p.182)
\end{abstract}

Nesse âmbito, como tem defendido pesquisadores como Santos (2009), o professor de Língua Portuguesa deve, na abordagem da literatura em contexto 
escolar de nível médio, assumir a posição de formador de leitores críticos de textos literários (BRASIL, 2006), a quem cabe contribuir ${ }^{2}$ para a promoção de uma educação literária que leve o jovem que frequenta os anos finais da educação básica brasileira não só a se apropriar com plenitude dos objetos estéticos produzidos nessa esfera - a literária - mas também de todo o patrimônio elaborado em torno desses objetos por meio do desenvolvimento de uma capacidade de leitura crítico-reflexiva que o permita (re)pensar e intervir sempre [n]o contexto sociocultural em que o discente se inscreve (LEAHY-DIOS, 2000; AZEVEDO, BALÇA, 2016)

\section{Da necessidade de desconstruir concepções cristalizadas para avançar na formação de leitores críticos de textos literários}

Como se percebe, toda essa movimentação acerca dos objetivos finais da escola no que se refere ao ensino de língua materna tem reorientado a abordagem do texto em sala de aula, em particular no que tange ao texto literário. Logo, considerando todo esse processo, novos entendimentos passam a ser demandadas, exigindo, dos professores formadores de leitores a superação, principalmente em relação ao ensino médio, de velhos projetos de condução da disciplina de Língua Portuguesa erigidos em um tempo pretérito no qual

1) o que se pretendia, no trato com o texto literário na disciplina de Língua Portuguesa de então era a transmissão de um saber legitimado sobre uma literatura canônica; 2) um foco seria dado à literatura como sinônimo de identidade nacional e como modelo de emprego da língua materna; 3) em termos de método - uma fidelidade à historiografia literária seria manifestada, assim como demonstrar-se-ia uma preferência por abordagens estruturalistas; e, principalmente, 4) a compreensão de aluno era a de mero receptor do saber "superior" que era a literatura (SANTOS, 2009, p.160).

\footnotetext{
${ }^{2}$ Cabe destacar aqui, como bem fundamentam Leahy-Dios (2000) - no Brasil - e Azevedo; Balça (2016) - em Portugal - que a educação literária é uma tarefa coletiva, transversal e contínua que envolve família, educadores, professores e outros inúmeros mediadores que atuam nos inúmeros espaços de formação que passam pela escola mas não se restringem a ela. Daí a opção deliberada pelo verbo contribuir nesta construção frasal. Isso não significa, no entanto, uma redução da importância do professor e da escola no processo de formação do leitor crítico de textos literários esperado da escola para o nível médio.
} 
Exatamente por identificar que esse velho projeto pedagógico terminou por se associar ao que se convencionou a ser chamado, no Brasil, de ensino de literatura, é que Santos (2017c), ancorado nas concepções hegelianas do conceito de trabalho, vem defendendo que o que deve ser feito na escola de ensino médio hoje, quando da abordagem do texto literário, é um trabalho com a leitura literária que alinhe as proposições de letramento literário Cosson (2014) com a perspectiva dos multiletramentos apresentada por Rojo e Moura (2012).

\begin{abstract}
Para Hegel (1971, p.90), ao lidar com a natureza por meio dos seus processos laborais, o homem desenvolve sua consciência, sua cultura, seu encontro consigo e com os outros, sua linguagem e seu mundo social. Uma abordagem do texto literário alinhada com as demandas atuais da escolarização regular deve, assim, acionar práticas pedagógicas que, em última instância, promovam um trabalho com a leitura literária que proporcione ao leitor/aprendiz esse deslocamento que, segundo Hegel, é resultado do trabalho humano. (SANTOS, 2017c, p.43-44).
\end{abstract}

Um elemento que exige tal mudança é que há, ainda segundo Santos (2011, 2017a) um perfil diferente de alunado presente na escola de nível médio dos dias atuais se comparado com público alvo para o qual as aulas de literatura foram pensadas entre o final do século XIX e primeiras décadas do século XX. Esse novo público, cada vez mais composto por jovens oriundos das camadas populares e com acesso restrito ao universo da leitura e da literatura canônica mas com razoável acesso às Tecnologias de Informação e Comunicação (TIC), veio fazendo com que os próprios discursos reguladores oficiais do ensino de língua portuguesa do país reconhecessem que há novos objetivos a serem alcançados pela escola regular na formação desse leitor (SANTOS, 2017b). Uma prova recente desse reconhecimento pode ser verificada, por exemplo, na argumentação que a recente Base Nacional Curricular Comum faz em relação à abordagem dos textos do que, nesse documento, é denominado como campo artístico-literário:

No campo artístico-literário busca-se a ampliação do contato e a análise mais fundamentada de manifestações culturais e artísticas em geral. Está em jogo a continuidade da formação do leitor literário e do desenvolvimento da fruição. A análise contextualizada de produções 
artísticas e dos textos literários, com destaque para os clássicos, intensifica-se no Ensino Médio. Gêneros e formas diversas de produções vinculadas à apreciação de obras artísticas e produções culturais (resenhas, vlogs e podcasts literários, culturais etc.) ou a formas de apropriação do texto literário, de produções cinematográficas e teatrais e de outras manifestações artísticas (remidiações, paródias, estilizações, videominutos, fanfics etc.) continuam a ser considerados associados a habilidades técnicas e estéticas mais refinadas. A escrita literária, por sua vez, ainda que não seja o foco central do componente de Língua Portuguesa, também se mostra rica em possibilidades expressivas. Já exercitada no Ensino Fundamental, pode ser ampliada e aprofundada no Ensino Médio, aproveitando 0 interesse de muitos jovens por manifestações esteticamente organizadas comuns às culturas juvenis (BRASIL, 2018, p. 495)

Ante a todo esse quadro, algumas rupturas com as imagens cristalizadas das aulas de Língua Portuguesa almejam formar o desejado leitor crítico de textos literários no ensino médio se fazem necessárias. Nesse âmbito, um primeiro movimento necessário é a desconstrução do entendimento reinante no Brasil do que é uma sala de aula, de quem são e como devem se comportar os agentes que atuam nesse espaço (professor e aluno), assim como de quais seriam os materiais e recursos didático-pedagógicos autorizados a transitar por esse espaço. Por mais óbvia que essa demanda possa parecer, principalmente se considerado o crescimento do discurso em torno da tecnologização da vida contemporânea, não é algo fácil de se conseguir em um espaço avesso a mudanças como as escolas. Isso porque, seja por restrições financeiras dos agentes públicos financiadores da educação formal, seja por limitação de mentalidade de gestores dos setores educacionais diversos, de docentes e de familiares, não tem sido fácil, sobretudo para escola pública brasileira de nível médio, romper o imaginário da velha sala de aula analógica, isolada do mundo lá fora, na qual transitam professores e alunos "de antigamente".

No que se refere ao docente, é de fácil compreensão que sua postura, nos anos finais da educação básica, lidando com jovens entre quinze e dezoito anos (ou seja, nascidos por volta dos primeiros quatro ou cinco anos do século XXI), em muito precisa se distanciar daquele modelo de professor/a com o qual nos habituamos nas faculdades de Letras e que, por muitos anos, foram "reproduzidos" sem conflitos nas salas de aula do ensino médio. Nas aulas de língua portuguesa em que se deseja uma abordagem da língua materna alinhada com as atuais 
demandas para o ensino médio, no que se refere ao trabalho com o texto literário, sai de cena o perfil de professor informador acerca dos textos, das obras, dos contextos de produção e das biografias dos autores e entra em cena um novo modo de existir como docente. Modo este que passa a exigir, também, outra relação professor/aluno:

\footnotetext{
Os meios de comunicação contribuíram para a recriação das relações entre educadores e alunos, pondo em crise o professor informador, para dar lugar ao educador-estimulador, ao comunicador, ao coordenador, ao facilitador da aprendizagem, deixando de ser o aluno o receptáculo passivo da informação para converter-se em agente-ator do processo de expressão e comunicação. (MUÑOZ, 2008, p. 78)
}

Por mais que não faltem discursos acadêmicos e não acadêmicos, personagens de séries e de programas de TV, propagandas, enfim, que veiculem um/a professor/a disposto/a a aprender com seus discentes e a reduzir as distâncias impostas pelo velho modelo eu-ensino-você-aprende, basta que se adentre a uma escola de nível médio, pública ou privada (sim! Nas escolas privadas também!) para encontrar, no que se refere às aulas de língua portuguesa do ensino médio, com velhos modelos didático-pedagógicos herdados das escolas inicialmente idealizadas para um alunado passivo, com medo do docente e incapaz de emitir uma opinião a não ser em um momento em que fosse chamado a fazê-lo.

Estando a escola inserida em uma sociedade que passa por mudanças, todo esse contexto supõe, como não poderia ser diferente, uma ruptura com a noção de aluno/a já cristalizada nas velhas concepções de ambiente escolar. Nestes termos, se já seria algo incompreensível desconsiderar as vivências dos/as alunos/as do ensino fundamental, sob o velho argumento de que a sua condição de menores de idade os/as impede de pensar autonomamente (SACRISTAN, 2005), mais incompreensível ainda é ter tal atitude em relação ao/à aluno/a do Ensino Médio. Alunos/as estes/as que, tendo vivido em média quinze anos dentro e fora da escola antes de iniciarem a última etapa da Educação Básica, já acumulam um número considerável de experiências de vida, de leitura do mundo (FREIRE, 2003) que o/a docente deverá saber mobilizar quando da construção dos sentidos dos textos literários.

Revista de Letras JUÇARA, Caxias - Maranhão, v. 03, n. 02, p. 37 - 57, dez. 2019 | 46 
Esse reconhecimento do/a aluno/a como sujeito ativo no processo de aprendizagem, demanda, por sua vez, um ajustamento entre as posições de professor/a e de aluno/a convencionadas pela estrutura escolar, colocando ambos/as, nas aulas de língua portuguesa, quando leitores/as, em uma situação que exige um minimizar do distanciamento tão cristalizado entre docente e discente, redirecionando-os ao posto de negociadores dos sentidos de um texto com o qual se trabalha (KOCH, 2009, p.17). Isso, contudo, não desconsidera o franco potencial do/a docente para ser um/a leitor/a mais experiente e, por isso, conduzir esses processos com seus alunos, reconhecendo que esse texto tem seus direitos e impõe limites à interpretação (ECO, 2008). Logo, as alterações demandadas pelos novos desenhos impostos à sala de aula e a seus agentes não descarta a presença de um/a professor/a cujo papel é de condutor/a da reflexão proposta, bem como não abandona um conteúdo formal na abordagem dos textos que ele/a seleciona.

Nesse cenário de alterações das concepções cristalizadas de ambiente escolar, um elemento gerador de certos incômodos tem sido o/a próprio/a professor/a estimular a inserção, nas suas atividades de leitura e produção de textos, do uso de Tecnologias de Informação e Comunicação (TIC) na promoção do processo de aprendizagem dos/as alunos/as. Mesmo sendo de domínio público que não há jovem presente hoje na escola de nível médio que desconheça por completo ferramentas como o aparelho de telefone móvel, grande tem sido o desgaste gerado, principalmente nas escolas públicas, por tentativas de impedir o uso das TIC no espaço escolar, criando uma oposição entre esses dispositivos e as aulas, como se não fosse impossível integrá-los em favor da aprendizagem do discente. Nestes termos, é pressuposto de uma formação escolar alinhada com as demandas deste século XXI a incorporação, na prática docente, do entendimento de que:

as novas tecnologias criaram novas chances de reformular as relações entre alunos e professores e de rever a relação da escola com o meio social, ao diversificar os espaços de construção do conhecimento, ao revolucionar processos e metodologias de aprendizagem, permitindo à escola um novo diálogo com os indivíduos e com o mundo. (MERCADO, 2002, p.01) 
Finalmente, no que tange à formação de leitores críticos de textos literários desejável como resultado das aulas de língua portuguesa do ensino médio, é necessário que se rompa, ainda, com a concepção de texto autorizado a adentrar o sagrado espaço da escola formal. Mesmo que já haja quase quatro décadas que obras como Invasão da catedral: literatura e ensino em debate, de Lígia Chiappini Moraes Leite, e O texto na sala de aula, de João Wanderlei Geraldi, defenderam, cada qual a seu modo, a importância de considerar o contexto em que se inscreve o/a aluno/a para a sua formação como leitor/a e produtor/a de textos, professores/as e instituições ainda se mostram avessos à ideia de que, respeitadas as restrições idade/maturidade do público alvo, todo texto é digno o suficiente para ser objeto de leitura e produção em uma aula de língua portuguesa. Razões para isso não faltam, indo das censuras e preconceitos velados que ainda permeiam o universo escolar até a pressão dos grandes conglomerados de editoras de livros e materiais didáticos, passando por comodismos pedagógicos produzidos pela reprodução de análises textuais prontas e fartamente exploradas tanto nos cursos de formação de professores de Letras quanto nas recentes videoaulas disponíveis aos montes em canais da internet.

Sem discordar da defesa feita por Cosson (2014) de que o letramento literário se alcança por meio da leitura efetiva de textos literários, não se pode ignorar que outros textos e outras linguagens podem ser acionados como forma de tornar o contato do jovem frequentador do ensino médio com o texto literário menos árduo.

Eis um outro dilema da disciplina de Língua Portuguesa do ensino médio:
deixar que artefatos culturais, textos e autores das culturas juvenis já tão
negligenciadas pela sociedade (Dayrell 2003; Dayrell, Carrano, Maia,
2014) possam frequentar os espaços formais de escolarização, sendo
objeto de reflexão tal qual ocorre, há tempos, com letras de cações de
Chico Buarque, com poemas de Gonçalves Dias ou com romances de
Machado de Assis.
Sendo a escola "poderosa na hora de abrir e fechar o cânone" (Costa,
2013 , p. 46) eleito como digno de frequentar as aulas de Língua
Portuguesa, é preciso que ela resista à tentação de, em nome da
preservação da tradição, restringir a pluralidade de textos autorizados a
transitar pelas aulas de língua materna realizadas no espaço escolar do
ensino médio, sob pena de ferir a sua condição de espaço público de Revista de Letras JUÇARA, Caxias - Maranhão, v. 03, n. 02, p. 37 - 57, dez. 2019 | 48 
formação (Zanfra, 2015) por excelência, mesmo quando esse espaço se localiza nos limites de uma escola privada. (SANTOS, 2018, p.351)

\section{Algumas ações docentes necessárias para a promoção do letramento literário de alunos dos anos finais da educação básica.}

Ante às proposições teóricas apresentadas no primeiro tópico deste texto e às desconstruções de tratou o segundo, que ações podem ser executadas por professores/as de língua portuguesa do ensino médio de modo a favorecer a promoção de um letramento literário efetivo dos jovens frequentadores dos anos finais da educação básica?

Um primeiro movimento, certamente, é a sondagem oral (em sala de aula mesmo) ou por escrito (Uma produção de texto convencional? Uma resposta a questionários via formulário Google? Um pequeno áudio ou texto de WhatsApp? Só para citar alguns exemplos...) que permita que o docente conheça os artefatos culturais aos quais seus alunos e alunas têm acesso: livros? Jogos? Músicas? Filmes? Séries? Em que suportes? Em que ambientes? Em que plataformas? Sobre que temas de interesse? Discutem sobre esses artefatos? Se sim? Onde? Quando? Com quem? Se não, por que não o fazem? Como gostariam de fazê-lo? Em encontros presenciais? Em suportes digitais? Há algum produtor de artefatos culturais na turma? Compositores/as? Escritores/as? Tocadores/as? Apresentadores/as? Todas essas informações, se reunidas pelo docente ou por alguém que por ele designado (como um/a representante de turma) podem fornecer consideráveis pistas sobre a produção de textos a partir da exploração de um poema, um conto, uma obra integral ou parte dela... que o/a professor/a desejar explorar.

Note-se que essa sondagem mencionada no parágrafo anterior supõe primeiramente, que o/a docente não trabalhará o texto literário pela mera obrigação do cumprimento do programa escolar, mas sim tem por interesse produzir algo com o artefato selecionado e/ou a partir dele, já supondo uma resposta a uma pergunta muito recorrente entre os alunos do ensino médio: o que eu vou fazer com esse texto/obra? Para quê eu vou ter que ler isso? Questões costumeiramente ignoradas pela escola regular, mas cuja importância da resposta é significativa para o Revista de Letras JUÇARA, Caxias - Maranhão, v. 03, n. 02, p. 37 - 57, dez. 2019 | 49 
adolescente que está no ensino médio. Outra prerrogativa da realização da sondagem citada nas primeiras linhas deste tópico é a de que a produção de textos não é algo separado do trabalho com o texto literário; tampouco se limita à produção de um texto escrito, podendo se materializar, a exemplo do que denota o trecho da Base Curricular Comum já citado neste ensaio, em um áudio (um podcast?) Um vídeo (A gravação de uma cena autoral? A reprodução filmada de uma cena existente em um texto escrito? Um podcast de vídeo? Um GIF? Uma animação a partir de recursos do celular?), um meme, uma charge, uma foto, um cartaz.... Uma terceira hipótese que dá sustentação à realização da compilação de informações já referida é a de que a prática do professor dará abertura para a realização de diálogos entre artefatos culturais vários, aproximando música, cinema, jogos digitais, textos não literários, gêneros não artísticos dos textos literários com os quais o/a professor/a vai trabalhar em sala de aula.

Outro movimento importante a ser realizado pelo/a professor/a de língua portuguesa que aspira operar com a condução de um letramento literário efetivo é conhecer o contexto social em que transitam seus alunos. Como seria, por exemplo, trabalhar os poemas satíricos de Gregório de Matos Guerra com estudantes que enfrentem os dilemas de uma sociedade que vive hoje os problemas que o autor baiano via na Cidade da Bahia do século XVII? Por que não explorar, com estudantes que vivem no campo, ou que trabalham na criação de gado, a visão pastoril dos poetas árcades? Qual a razão de não aproximar os dramas amorosos dos inúmeros escritores românticos dos conflitos juvenis em torno das paixões inerentes àqueles/as estudantes do ensino médio? Tais dramas continuam os mesmos nesses tempos digitais? Há solitários nesses tempos? Há idealistas? Há sonhadores? Os perfis de homens, de mulheres, de casal do Romantismo continuam atuais? E as denúncias sociais do Realismo-Naturalismo do final do século XIX? Estão presentes no dia a dia do alunado que frequenta as aulas de língua portuguesa nos anos finais da educação básica? Eles enfrentam preconceitos, intolerâncias, traições, frustrações no amor e na amizade... como os personagens de Machado de Assis, de Aluísio Azevedo ou de Raul Pompeia enfrentam? Há lugar, na vida fora da escola pela qual os estudantes do ensino médio transitam, para um artista alienado como proposto por certa corrente 
parnasiana? Há lugar para uma sensibilidade sinestésica simbolista? E os projetos de ruptura artística propostos pelos escritores modernistas do século XX? Podem ser associados com o engajamento visto nos escritos dos muros nas ruas por onde esses/as estudantes transitam? Estão nos raps que dançam e escutam?

Não é difícil supor o quanto respostas para as muitas questões feitas nesta página podem ser úteis para a condução de uma abordagem de certos textos literários pelo/a docente de língua portuguesa do ensino médio, desde que ele/a tenha sensibilidade para buscar informações como as mencionadas junto ao seu grupo de discentes ou junto à comunidade em que a escola se insere, por meio de uma conversa ou com os/as próprios/as alunos/as ou com pessoas que conheçam as comunidades em que as escolas se localizam.

Uma vez realizados os passos acima mencionados, um trabalho com a leitura literária alinhado com as demandas atuais para a formação de leitores críticos de textos literários supõe outros movimentos por parte do/a professor/a de língua portuguesa do ensino médio. Um desses deslocamentos é o reconhecimento do potencial dos projetos de leitura para a formação do leitor crítico de textos literários almejado pela legislação do ensino médio em vigor no Brasil. Nesse sentido, cabe destacar que, para o âmbito deste ensaio, um projeto de leitura está sendo entendido como a condução de ações que envolvam a leitura literária com vistas a resolver um problema e gerar um produto ao final de um determinado percurso. Tal entendimento, livremente inspirado nas teorizações que dão sustentação à Pedagogia de Projetos (DEWEY, 1967; LEITE 1996), supõe que, para o trabalho com a leitura literária, o/a professor de língua portuguesa do ensino médio será capaz de identificar um tema, apontar um problema, selecionar textos que possam contribuir para a realização de uma reflexão que permita apontar soluções para esse problema por meio do acionamento da leitura literária e de outros leituras, culminando em uma produção textual. 
A título de exemplo, veja-se a instrução apresentada no quadro abaixo:

O Primeiro Modernismo Brasileiro (1922-1930) compreende um grupo de artistas diversos que se pautaram por um paradoxo: ao mesmo tempo em que faziam ruptura com os padrões artísticos vigentes até então, propunham um resgate de elementos típicos da tradição cultural de diversas regiões do Brasil. Tal paradoxo não desaparece das manifestações artísticas nacionais com a passagem da primeira para as demais fases do Modernismo. Tendo em vista esta contextualização, a leitura integral da obra Macunaíma, de Mário de Andrade, as consultas ao material sobre a primeira fase do Modernismo existente no livro didático (e em outras fontes que desejar consultar), bem como as diversas manifestações artísticas mencionadas nos links apresentados pelo professor, elabore um podcast de áudio de, no máximo três minutos, sobre o tema PERMANÊNCIA DO PROJETO DO PRIMEIRO MODERNISMO NAS MANIFESTAÇÕES ARTÍSTICAS BRASILEIRAS DOS SÉCULOS XX E XXI.

A proposição acima abriria uma sequência de aulas de língua portuguesa do último ano do ensino médio cujo interesse seria, como se percebe, estudar o Primeiro Modernismo a partir da leitura de uma obra pouco simpática aos modos de vida atuais dos/as estudantes do ensino médio. O/a docente que a elaborasse, no entanto, partiria das sondagens citadas no início deste tópico, identificando o apreço dos/as alunos/as por obras que propusessem algum tipo de ruptura aos padrões convencionais de arte, fosse no cinema, na música, na pintura, na literatura, em séries de TV, jogos digitais, entre outros. O/a professor/a também identificara, entre seus/suas discentes, o interesse pela produção de podcast de áudio, estimulados pela edição de programas da rádio escolar que os próprios alunos conduzem na escola. De posse de tais informações, o/a docente construiria, com a ajuda do alunado, o enunciado acima, dando início a uma sequência de aulas que, quando voltadas para o trabalho com o ensino de língua, exploraria a "leitura" do podcast e de outros arquivos de áudio, trabalhando as especificidades da comunicação oral, suas estratégias de persuasão (a impostação da voz, o uso de música incidental, a utilização de vinhetas e onomatopeias, o aumento ou diminuição de volume...).

Quando voltado para o trabalho com a leitura literária, o trabalho do/a docente seguiria a proposta de Cosson (2014) já referida neste texto para apresentar a obra Macunaíma, de Mário de Andrade, selecionando dois capítulos do livro para ler com os alunos em sala, projetando-os na tela do projeto multimídia 
e disponibilizando-os para os alunos via WhatsApp para que pudessem acompanhar a leitura e fazer marcações, interagindo com o professor. Nesse processo de leitura, o professor exploraria os experimentalismos linguísticos propostos pelo escritor modernista, sua ruptura temática, linguística e estrutural em relação às narrativas que o antecederam $e$, dados os interesses do projeto de leitura, destacaria a rica exploração que o autor fez do folclore e da cultura brasileira na composição do seu anti-herói. Tudo isso feito por meio de aulas dialogadas, com perguntas pontuais feitas para os/as alunos/as, estimulando a interação nas aulas de exploração do texto literário.

Feito todo esse percurso, o professor, de posse da informação do grande interesse da turma em causa por música brasileira, apresentaria para seus alunos os links descritos no quadro abaixo, a partir dos quais eles deveriam, reunidos em grupo, no Laboratório de Informática da Escola, acessar os endereços, selecionar um artefato para o grupo, analisá-los conforme instrução da tarefa apresentada no início e reunir informações para elaboração do podcast.

https://pt.wikipedia.org/wiki/Secos \%26 Molhados [Verbete que informa sobre a banda Secos e Molhados e comenta algumas de suas marcas, as quais podem ser associadas ao projeto do Primeiro Modernismo]

https://www.youtube.com/watch?v=MZYg1aGxOWA [Vídeo da Música Flores Astrais, da Banda Secos e Molhados. Atentar-se para as rupturas não só na composição visual da apresentação, mas também na instrumentação e letra da música]

https://www.youtube.com/watch?v=gfs9DC4GNr0 [Apresentação da Banda Os mutantes, com a canção Panis et circenses. Prestar atenção na instrumentação e na letra da música]

https://www.youtube.com/watch?v=XmRoH8IQB4M [Breve projeção que explica - com exemplos - o que foi o Movimento Tropicalista e quais são os artistas que o realizaram, bem como menciona desdobramentos desse movimento]

https://www.youtube.com/watch?v= G63uF288T4 [Clipe da música Maracatu Atômico, com performance de Chico Science \& Nação Zumbi. Atentar-se para os processos inovadores de composição do vídeo, bem como para os diferentes planos de filmagem.]

Feito esse movimento, o/a docente dedicaria uma aula para que os/as alunos pudessem, depois de discutirem via grupos de WhatsApp, finalizar o podcast a partir da utilização de ferramentas disponíveis ou nos aparelhos celulares de integrantes do grupo ou nos computadores da escola, sob a supervisão do professor de língua portuguesa e do professor de informática ou de um convidado 
do primeiro que se dispusesse a auxiliar os/as discentes na finalização dos produtos, os quais seriam apresentados para o público interessado em um dia decidido em assembleia envolvendo os/as discentes e o/a professor/a de língua portuguesa.

\section{Considerações finais}

Ser professor/a de língua portuguesa no ensino médio brasileiro não tem sido uma tarefa fácil nos tempos atuais, tendo em vista as consideráveis alterações a que o universo juvenil - público alvo potencial desse nível de ensino - tem sido submetido nesses tempos com fortes rupturas de valores, de proposição de projetos de vida alternativos e grande presença das Tecnologias de Informação e Comunicação. Menos fácil ainda tem sido a tarefa de manter a conexão entre o público potencial do ensino médio e a cultura literária produzida em torno de autores e obras cuja leitura continua a ser central para a formação de sujeitos críticos que conduzirão a nação em tempos futuros.

Tendo esses desafios em consideração e respondendo a um estímulo feito por diversos professores com os quais foram feitas interlocuções em cursos de formação continuada ofertados em diferentes contextos é que foi configurando o presente texto, deliberadamente classificado como um ensaio. Tal classificação foi selecionada exatamente pela liberdade que um ensaio fornece ao autor, permitindo que seja feita uma reflexão livre sobre determinado tema, sem a pretensão de esgotá-lo.

Conforme escrito nas palavras iniciais deste texto, o que se espera é que ele seja objeto de interações entre professores de língua portuguesa e formadores desses professores, de modo que as informações e ideias aqui expostas possam ser objeto de críticas, de discordâncias, de aceitações integrais ou parciais... O importante, para as pretensões deste ensaio, é que ele gere alguma discussão acerca deste tema urgente e central para a escola básica brasileira: a formação de leitores críticos de textos literários e de um público que saia do ensino médio com melhores índices de letramento que os que têm sido verificados no país. 


\title{
CHANGES IN THE ACTION OF PORTUGUESE LANGUAGE TEACHERS OF BRAZILIAN HIGH SCHOOL TO PROMOTE LITERARY LITERACY.
}

\begin{abstract}
When it comes to discussing actions for the promotion of literacy that actually qualify competent users of the Portuguese language, Brazilian high school is undoubtedly a context that requires more careful reflection, given its difficulties to deliver to the society young people with a minimally qualification desirable from this level of education. In this context of the final years of Brazilian basic education, even more complex is the issue of the formation of the critical reader of literary texts desired by the official speeches that regulate mother tongue teaching in the country. Against this background, this essay reflects on the changes that new theoretical perspectives for mother tongue teaching impose on to work with the literary text in the universe of the high school classroom and on how such changes point to the need for that also the action of the teacher of Portuguese language in this context changes. This is a reflection that meets the demand of Portuguese-speaking teachers from the final years of Brazilian basic education who, in various continuing education courses, always question what new directions can be applied to the ways of conducting education approach of the literary text to the young public that Brazilian high school potentially attends.
\end{abstract}

Keywords: Work with literary reading. Literary Literacy. Brazilian High School. Teacher action.

\section{Referências}

AZEVEDO, Fernando; BALÇA, Ângela (Coords.). Leitura e Educação Literária. Lisboa: Pactor, 2016.

BRASIL. Ministério da Educação. Base Nacional Comum Curricular. Brasília: Ministério da Educação, Secretaria de Educação Básica, 2018.

BRASIL. Ministério da Educação. Secretaria de Educação Média e Tecnológica. Parâmetros Curriculares Nacionais: ensino Médio. Brasília: Ministério da Educação, 1999.

BRASIL. Ministério da Educação. Secretaria de Educação Básica. PCNEM+ Ensino Médio: Orientações Educacionais Complementares aos Parâmetros Curriculares Nacionais. Linguagens, Códigos e suas Tecnologias. Brasília: Ministério da Educação, 2002.

BRASIL. Ministério da Educação. Orientações curriculares para o ensino médio. Linguagens, códigos e suas tecnologias / Secretaria de Educação Básica. Brasília: Ministério da Educação, Secretaria de Educação Básica, 2006.

COSSON, Rildo. Letramento literário: teoria e prática. São Paulo: Contexto, 2014.

COSSON, Rildo. Letramento literário: uma localização necessária. Revista Letras e Letras. v. 31, n. 13 (jul/dez 2015. p. 173-187. 
DEWEY, Jonh. Vida e Educação. Tradução Anísio S. Teixeira. 6. ed. São Paulo: Melhoramentos. 1967.

ECO, Umberto. Os limites da interpretação. 2.ed. Tradução de Pérola de Carvalho. São Paulo: Perspectiva, 2008.

FREIRE, Paulo. A importância do ato de ler: em três artigos que se completam. 45.ed. São Paulo: Cortez, 2003.

GERALDI, João Wanderlei. (Org.). O texto na sala de aula. São Paulo: Ática, 2003. KATO, M. No mundo da escrita: uma perspectiva psicolingüística. São Paulo: Ática, 1986.

KLEIMAN, Angela B. O que é letramento: uma nova perspectiva sobre a prática social da escrita . Campinas: Mercado de Letras, 1995a.

KLEIMAN, Ângela B. (Org.) Os significados do Letramento: uma nova perspectiva sobre a prática social da escrita. Campinas, SP: Mercado das Letras, $1995 \mathrm{~b}$.

KOCH, Igedore G. V. Desvendando os segredos do texto. 6.ed. São Paulo: Cortez, 2009.

LEAHY-DIOS, Cyana. Educação literária como metáfora social: desvios e rumos. Niterói: EDUFF, 2000.

LEITE, L. C. M. Invasão da catedral: literatura e ensino em debate. Porto Alegre: Mercado Aberto, 1983. (Novas perspectivas, 6).

LEITE, L.H.A. Pedagogia de Projetos: Intervenção no Presente. Presença Pedagógica, Belo Horizonte: Dimensão, v. 2, n. 8, p. 25 - 33, mar/abr 1996.

MERCADO, L. P. L. A internet como ambiente auxiliar do professor no processo ensino-aprendizagem. In.: Conferencia Internacional sobre Educatión, Formación y Nuevas Tecnologías y e-Learning, 2002. Sevilla, Espanha.Actas de Virtual Educa 2002. Sevilla, Espanha: Virtual Educa, 2002, v.1. p.1-12.

MUÑOZ, R. F. Las nuevas tecnologías aplicadas a la educatión en la formación inicial del profesorado: a modo de justificatión. Docencia e Investigatión. Revista de la Escuela Universitaria de Magisterio de Toledo. Año XXI, enero-diciembre, 2008. p.77-100.

PAULINO, Graça. Letramento literário: cânones estéticos e cânones escolares. Caxambu: ANPED, 1998 (Anais em CD ROM).

ROJO, Roxane; MOURA, Eduardo. Multiletramentos na escola. São Paulo: Parábola Editorial, 2012. 
SACRISTÁN, José Gimeno. O aluno como invenção. Porto Alegre: Artmed, 2005.

SANTOS, Rodrigo Alves dos. Cartografando a construção do atual perfil de leitor de textos literários egresso das aulas de língua portuguesa do ensino médio. Revista Brasileira de Educação. Revista Brasileira de Educação, v. 22, n. 71, 2017a. Disponível em: <http://bit.ly/2AAQZcr>. Acesso em: 13 nov. 2019.

SANTOS, Rodrigo Alves dos. Conhecendo o perfil do jovem demandado pelo discurso oficial sobre o "novo" Ensino Médio. In.: CARVALHO, Carlos Frederico Vaz de; FRAGA, Fernando Caramuru Bastos; ROSA, José Henrique Alves; ARÃO, Lilian Aparecida (Coord). Dez olhares sobre juventude e cultura. Belo Horizonte: Fundação Guimarães Rosa, 2011. p.75-85

SANTOS, Rodrigo Alves dos. Do professor de literatura ao formador de leitores críticos de textos literários: um estudo sobre a (re)invenção do professor de língua portuguesa para o trabalho com a leitura literária no Ensino Médio. 200f. Tese de doutorado (Doutorado em Educação) - Faculdade de Educação - Universidade Federal de Minas Gerais (MG), 2009.

SANTOS, Rodrigo Alves dos. Elementos para começar uma conversa sobre a formação de formadores de leitores críticos de textos literários para atuação no Ensino Médio. Revista de Letras. Curitiba, v. 19, n. 26, p. -34-52, set. 2017c.

SANTOS, Rodrigo Alves dos. Para uma abordagem do texto literário no ensino médio alinhada com as demandas contemporâneas da educação formal. In. SOUSA, Ivan Vale de. (Org.). Leitura na educação básica: perspectivas e desafios. Jundiaí: Paco Editorial, 2017b. p.115- 132.

SANTOS, Rodrigo Alves dos. Sobre as aulas de língua portuguesa no ensino médio: velhos dilemas, algumas proposições. In.: ANDRADE, Maria Eufrásia Barreto de; ESTRELA, Sineide Cerqueira; SILVA, Irlana Jane Menos da. (Orgs). Políticas e Práticas Educacionais: dilemas e proposições. Jundiaí: Paco Editorial, 2018. p.345-359.

SOARES, Magda. Letramento: um tema em três gêneros. 2. ed. 8.reimpr. Belo Horizonte: Autêntica, 2004.

Data da Submissão: $14 / 11 / 2019$

Data da Aprovação: 26/12/2019 